\title{
'Coming Down the Line' - Patients' Understanding of Their Family History of Common Chronic Disease
}

\author{
Fiona M. Walter, MA, MSc, FRCGP \\ Jon Emery, DPbil, FRACGP ${ }^{2}$ \\ ${ }^{\prime}$ General Practice \& Primary Care Research \\ Unit, Department of Public Health \& \\ Primary Care, Institute of Public Health, \\ University of Cambridge, Cambridge, UK \\ ${ }^{2}$ General Practice, School of Primary, \\ Aboriginal and Rural Health Care \\ (SPARHC), University of Western Australia, \\ Claremont, Western Australia, AU
}

\begin{abstract}
PURPOSE The family history is becoming an increasingly important feature of health promotion and early detection of common chronic diseases in primary care. Previous studies of patients from genetics clinics suggest a divergence between how persons with a family history perceive and understand their risk and the risk information provided by health professionals. This interview study aimed to explore how patients in primary care understand and come to terms with their family history of cancer, heart disease, or diabetes and how family history might affect consultations about disease risk and management.
\end{abstract}

METHODS Thirty semistructured interviews were conducted with general practice patients who had a family history of cancer, heart disease, or diabetes. The transcript data underwent a qualitative constant comparative analysis.

RESULTS What exactly constitutes having a family history of an illness varied among participants. The development of a personal sense of vulnerability to the illness in the family depended not only on the biomedical approach of counting affected relatives but also on a sophisticated interplay of other factors. The emotional impact of witnessing the illness in the family, particularly if the illness was sudden, premature, or fatal, and the nature of personal relationships within a family that determine a sense of emotional closeness and personal likeness with the affected relative, all contributed to the perception of disease risk. Different beliefs about the contributions of nature and nurture to disease can affect patients' views on the degree of control they can exert over their risk.

CONCLUSION This study highlights potential differences between the way patients and medical professionals assess and understand familial risk of cancer, heart disease, and diabetes. Our previous systematic review findings are enhanced by showing that personal experience of disease and the emotional impact can also influence familial risk perceptions. Eliciting the patient's perspective when discussing risk of chronic disease, particularly in the context of a family history, could inform a more patient-centered approach to risk assessment and communication and support patients to make informed decisions about the management of their disease risk.

Ann Fam Med 2005;3:405-414. DOI: 10.1370/afm.368.

\section{INTRODUCTION}

$\mathrm{T}$ aking a family history is an increasingly important component of chronic disease prevention in primary care. In the United Kingdom, the NHS National Service Frameworks (guidelines) for coronary artery disease, diabetes, and cancer ${ }^{1}$ highlight the relevance of the family history as part of risk assessment and management. Accurate assessment and effective communication of familial risk enables appropriate reassurance for those who are at population risk and the discussion of treatment options or behavior changes for those at increased risk. ${ }^{2}$ The role of the 
family history in clinical practice is therefore likely to expand from providing the traditional psychosocial insights into the context for a patient's symptoms of disease to also include risk assessment and management. ${ }^{3}$ Effective risk communication is a complex process that could be facilitated by adopting a patientcentered approach of incorporating patients' ideas, feelings, and concerns. ${ }^{4}$

Social science research suggests that health professionals and patients may hold different views about health and illness: while the professional perspective is informed by biomedical models, the patient's perspective is more likely to be based on their illness experiences. ${ }^{5}$ Knowledge about patterns of inheritance are part of family culture in Euro-American and other cultures in which a wide range of diseases and characteristics are believed to run in the family. ${ }^{6}$ Clinicians should be aware of how their patients' understand their family history, as this understanding will influence perceptions of both their risk of the disease and its management. ${ }^{7}$

Disease-related risk perceptions, as well as the relationship between risk perception and health behaviors, have been studied extensively. Structured models have been developed to integrate differing health beliefs and to understand their role in predicting health-related behaviors. Among the most influential models is Leventhal's seminal theoretical work, the Common Sense Model of Self Regulation (CSM), which arose from the observation that the medical definition of symptoms represented only one type of perceptual information needed to appraise a health-risk situation. The biopsychosocial factors that influence the representations of each of its key components were also identified: perceived health threat, potential health behavior(s), and perceived impact of engaging in those behaviors. ${ }^{8}$ The CSM has been widely used to examine how patients evaluate health threats by constructing their own representations or perceptions that influence their patterns of coping. ${ }^{9}$ If a perceived family medical history is viewed as a health threat, then the CSM may also be used to interpret patients' understanding of their family history of common chronic disease.

We recently reported a synthesis of qualitative studies that explored how people understand a family history of cancer, coronary artery disease, or diabetes. ${ }^{10}$ We developed a theoretical framework to explain the processes by which a person develops and deals with personal perceptions of disease risk. It reflects several of the constructs of the CSM. Most of the studies included in our previous review were based on patients sampled from specialist care whose beliefs may have been altered by some form of genetic counseling. This qualitative study tests the theoretical model with patients from general practice. We aimed to explore understanding about family history and familial risk of common chronic disease in primary care patients.

The study was approved by the Cambridge Local Research Ethics Committee.

\section{METHODS}

\section{Participants}

Our sampling strategy aimed to gain the broadest view possible by reflecting a range of age, sex, social class, educational levels, and degree of familial risk. Participants were recruited from 2 Cambridgeshire general practices: practice 1 (list size 2,236; 30\% younger than 18 years; $1 \%$ older than 75 years) was located in a developing semirural new town, while practice 2 (list size $10,564,21 \%$ younger than 18 years; $8 \%$ older than 75 years) was located in the city of Cambridge. Electronic searches of practice medical records looked for patients aged 18 years and older with a first-degree relative with either cancer, coronary artery disease, or diabetes. In each practice 30 patients with a family history of each disease were randomly selected by the EMIS clinical computer system, generating a total sample of 180. General practitioners (GPs) excluded patients who were unable to communicate in English or had severe mental disability or life-threatening disease. Patients were approached by a single letter from their GP.

\section{Interviews}

Semistructured qualitative interviews lasting about 1 hour were conducted mainly by the first author in the interviewees' homes between October 2002 and March 2003. The interview guide was informed by our systematic review ${ }^{10}$ and pilot tested with the first 5 participants (the interview schedule can be found online only in Supplemental Table 1, available at: http://www. annfammed.org/cgi/content/full/3/5/405/DC1). Considerable flexibility during the interviews allowed participants to discuss issues that were most important to them. Participants gave details about their relatives' health or cause of death to initiate discussions about their family history and its personal meaning.

\section{Analysis}

Audiotapes of the interviews were fully transcribed, and analyzed manually, supported by NUD*ST software. ${ }^{11}$ Although we were testing the theoretical model, we were concerned that using an analysis strategy, such as framework analysis, ${ }^{12}$ may have obscured emerging and previously unrecognized themes. We therefore applied a constant comparative technique ${ }^{13}$ to allow the emergence of themes and development of underlying concepts, and later we mapped the emerging concepts onto the theoretical model. This approach allowed 
both the confirmation of the main constructs and the identification of further concepts leading to changes and refinement of the model. Analysis began during data collection to inform subsequent interviews, which were continued until data saturation was achieved. Analysis was conducted primarily by the first author, with half the transcripts independently read by the second author to confirm the integrity of the emerging themes and concepts. The quotations that follow were chosen to reflect a range of both consensual and dissenting views.

\section{RESULTS}

\section{Participants}

Eighty-nine patients were approached from practice 1, of whom 20 responded; 90 patients were approached from practice 2 , and 24 responded, giving an overall response rate of $25 \%$. Telephone contact with each respondent confirmed they had at least 1 first-degree relative with cancer, coronary artery disease, or diabetes. Thirty-two patients were available for interview, and 2 dropped out at the time of interview, 1 because of personal illness and 1 moved away. By the time 30 interviews were completed, no new themes were emerging. Participants' characteristics are shown in Table 1. Three-generation family histories were recorded, and participants had 1 to 5 affected relatives. More than one half of the participants had more than 1 first-degree relative with cancer, coronary artery disease, or diabetes, and $5(17 \%)$ had a family history of all 3 diseases. On current risk assessment criteria for cancer ${ }^{14-16}$ and coronary artery disease, ${ }^{1}$ only a minority would be considered to be significantly above the population risk for their age. Eight participants (27\%) had chronic conditions, including asthma, depression, hypothyroidism, Parkinson's disease, and osteoarthritis, while 3 participants had had bypass surgery for coronary artery disease, and 2 had diabetes.

\section{Understanding Family History}

Our results confirm the constructs of the theoretical model derived from specialist care, and further themes emerged that have been used to refine the model (Figure 1). Once a person acknowledges that an illness runs in the family, the family history grows in meaning through many routes until there is gained a sense of vulnerability to the disease, which the person then attempts to cope with or control. Concepts about personal relationships within a family that determine a sense of risk, the effects of personal experience of familial illness on risk perception, and strategies patients apply to cope with or control their familial risk were themes that took on particular importance.

\begin{tabular}{|c|c|}
\hline Characteristic & No. (\%) \\
\hline \multicolumn{2}{|l|}{ Practice } \\
\hline Practice 1 & $12(40)$ \\
\hline Practice 2 & $18(60)$ \\
\hline \multicolumn{2}{|l|}{ Family history of disease } \\
\hline Cancer & $14(47)$ \\
\hline Heart disease (coronary artery disease) & $15(50)$ \\
\hline Diabetes & $7(23)$ \\
\hline \multicolumn{2}{|l|}{ Age, years } \\
\hline $20-39$ & $12(40)$ \\
\hline $40-59$ & $14(47)$ \\
\hline $60+$ & $4(13)$ \\
\hline Sex, female & $16(53)$ \\
\hline \multicolumn{2}{|l|}{ Ethnic origin } \\
\hline White & $28(93)$ \\
\hline Other (Japanese 1, Iranian 1) & $2(7)$ \\
\hline \multicolumn{2}{|l|}{ Marital status } \\
\hline Single, widowed, divorced & $4(13)$ \\
\hline Married, living with partner & $26(87)$ \\
\hline \multicolumn{2}{|l|}{ Children } \\
\hline No & $7(23)$ \\
\hline Yes & $23(77)$ \\
\hline \multicolumn{2}{|l|}{ Education } \\
\hline Primary education only & $2(7)$ \\
\hline 2 = Some secondary education & $7(23)$ \\
\hline 3 = Completed O-levels (to 16 y) & $7(23)$ \\
\hline $4=$ Completed A-levels (to $18 \mathrm{y}$ ) & $5(17)$ \\
\hline $5=$ Further education & $9(30)$ \\
\hline
\end{tabular}

\section{Confirming the Familial Risk Model}

\section{It Runs in My Family}

The great majority of participants viewed cancer, coronary artery disease, or diabetes as "running in the family" or "coming down the line." What exactly constituted having a family history of an illness varied among participants: whereas it meant having more than 1 affected relative to most participants, several considered an illness to run in the family when only 1 relative had suffered the illness. This finding occurred across all 3 diseases studied.

"The heart disease does seem to run in our family, because I lost my mother and aunt to it, and I've just lost my cousin to it, but not so much the cancer, because my dad was the only one that's had it" (ID03; female; 42 years).

"I know with cancer in my family, my grandparent who had it was on my dad's side, but my mum had it and my sister had it, and you sort of think, mm'hmm, 2 out of 3 of us, this is quite high, is it coincidence or something else" (ID16; female; 52 years)?

"I feel more at risk because of my father, so [diabetes] is in the family, but only my father [is affected].

I think genetically there is a weak link there: it could 


\section{Figure 1. Model of familial risk perception.}

Note: How persons with familial risk develop and manage their personal sense of vulnerability-changes and refinements based on findings from the interview study.

From Systematic Review/Synthesis

Patients mainly from specialist clinics

Number of affected relatives and age(s) at diagnosis or death

Severity of illness: premature or fatal

Living through relative's illness experience

Comparing similarities and differences with affected relatives

Patterns of ages or sex

Models of health and illness, disease causation and inheritance

Notions of bad luck and fatalism

Behavior change, eg, lifestyle

Undergoing disease screening

Acceptability of disease as illness

or mode of death

Continued anxiety
New affected relative

From Interview Study

Patients from primary care

Closeness; emotional bond

Personalizing

process

Likeness: similarities with affected

relative(s) of personality, mannerisms,

feelings, and looks

Limiting personal vulnerability:

"bargaining" and counterexamples

Vulnerability in other family members, such as siblings

Vulnerability in offspring

Control the risk, eg, lifestyle

Fatalism

Empowerment

Screening and self-examination miss me altogether, and that'd be fine, but then it could be there as well" (ID22; female; 45 years).

Explanations for why they believed a disease ran in the family were not solely based on inherited mechanisms. The differing contributions of nature and nurture were widely discussed: most participants described a multifactorial model of familial risk, and few participants viewed the development of illness as solely due to inheritance. Environmental or lifestyle causes for a relative's illness were often reported, but when there was no obvious cause for a relative's illness, inherited factors were more likely to be implicated.

"Well there are certain traits you know, familial traits, and I think they're probably causing illnesses, but I certainly don't think it's the whole picture, I think that environment and nurture play a part as well" (ID06; female; 58 years).

"My grandfather wasn't a great smoker and got lung cancer, my father's had blood cancer, leukemia, and I can't see any obvious surrounding factors that would influence [either]. My experience has led me to think that it is a genetic, more than a surrounding thing" (ID18; male; 37 years).

Environmental and lifestyle factors were often discussed in terms of triggering an underlying inherited risk:
"My father has been diagnosed with diabetes, and I believe that was triggered off by 2 factors actually, by diet because he was overweight at one stage and he did eat a lot of the wrong food, but also he had a very stressful time in his life that came about through a work situation, and I think that stress factor was the trigger to bring on the diabetes" (ID22; female; 45 years).

Some acknowledged that shared environmental, as opposed to genetic, factors could explain their family history, and a few discussed the contribution of chance or bad luck. For a few participants this developed into a fatalistic attitude of inevitability developing the illness in their family.

"My sister and I, we are doomed: dad's had a quadruple bypass, and his father had strokes, and there's high cholesterol on his side of the family" (ID07; female; 44 years).

"I suppose I'm a bit of a fatalist: I've smoked since I was 14 , so I would have thought if there's anything gonna happen to me, that's something that had to happen" (ID21; male; 59 years).

About one third of participants spontaneously mentioned genes, usually in connection with transmission of traits or illnesses. When their understanding about genes was explored further, however, most participants 
were vague or even defensive. Understanding the mechanisms of inheritance was important only to a minority with concerns about the risk of familial illness for their children.

"If you inherit bad genes, then you are predisposed to have something wrong, and if you inherit strong genes, then you'll prosper, and it's not quite so straightforward to say just because my father's got it, right, because that's only half of where I come from" (ID09; male; 52 years).

"I suppose my knowledge is very limited except I just think it's something that transmits from one generation to another. It's like a blueprint... I feel as if I'm doing my A levels" (ID05; female; 60 years).

\section{Routes to Feeling at Risk}

Acknowledging that a family history of a disease does not equate with feeling personally at risk for the illness. The route to feeling at risk describes how the family history gains personal meaning, such as the emotional impact of witnessing a relative's illness or death and the course of that illness.

Emotional impact of witnessing a relative's illness. Experiencing a relative's illness, recovery, or death, particularly a parent or sibling, contributed to the participants' understanding of the illness itself as well as perceptions of personal risk. Participants described their relative's illness in a chronological and detailed way, long after the event, including the emotional effects of witnessing the illness, guilt at being unable to alleviate suffering, or regret about the limited time spent with their relative before their death.

"My father died of cancer, so we were involved in it quite dramatically, and I think when it's a family member, you never forget. I think when it's somebody from the outside, then for a period of time, you get this immediate shock, then it sort of fades. But when it's your father, you never forget what actually happened" (ID09; male; 52 years).

The impact of witnessing illness was not confined to cancer but was also discussed in relation to coronary artery disease and diabetes. Witnessing the illnesses of more distant relatives or friends added to their understanding of the illness but had less impact on their feeling at risk.

"There's the thing of the genes again: if it's the relative ... I could have similar things to them. We don't really think about that with a friend" (ID19; female; 27 years).

A few participants felt that witnessing an illness alone did not affect their sense of personal risk and that only by developing the illness themselves would they fully understand its importance.

"A heart attack is something that me mum's talked about, and she's told me about [her own], but it's not something that I've had any experience of, you know, personally. You sort of tend to shunt that to the background a bit, you know" (ID08; male; 39 years).

Course of the relative's illness. The onset, course, and outcome of the relative's illness further contributed to the participants' feeling at risk. Sudden illness, particularly sudden death, prolonged illnesses, or a silent onset of the illness, were important routes to feeling at risk:

"[My mum] was far too young at 45 to be dying from a heart attack. It wasn't as though she had a number of warnings, it was very sudden and that's it, just had a heart attack one day. That is much more of a threat hanging over you I suppose" (ID17; female; 38 years).

The perception that the death was premature gave it more weight and was applied even when relatives died in their 60 s or 70 s.

"My father was the most youthful of his generation, never a day's illness, so to die at 65 is young, you know, he was taken too young. He still had lots of things he could do, I mean for others as well for themselves, and that's the sad thing, because he was so energetic, squash playing, full of life, getting things out of people.... That is for us a huge part of the loss" (ID18; male; 37 years).

Symptoms or signs that appeared late in the course of the disease or delayed diagnoses, with sometimes a much stormier course of illness, also contributed to the personal meaning of the family history.

"[My mother] was 47 or so when she died, but we never knew where [the cancer] originated from, it was lots of missed diagnoses, and at the time it was diagnosed it was sort of everywhere so ... no idea where it started from. And really there's nothing you can do" (ID16; female; 52 years).

Survival and return to a nearly normal lifestyle, especially for coronary artery disease and diabetes, meant the illness and their family history were less threatening.

"I think it probably seems less serious to have heart trouble [than cancer], as the majority of my relatives have survived, and 2 of them are living relatively healthily. So there is something about outcomes as well in a way" (ID14; male; 31 years).

Patterns within the family history. Participants sometimes tried to identify patterns within their family history when considering their own risk. Examples included patterns of life events, such as age of onset of illness, or the sex of family members affected by the illness.

"[Cancer] definitely is a female thing on my side, in my mind. When I came up to the same sort of age as my Mum [when her breast cancer was diagnosed], it 
was a very tense time. I think once I'd gone over 50 I felt safer almost" (ID 16; female; 52 years).

\section{Refining the Familial Risk Model}

Routes to Feeling at Risk

Further themes emerged that underpin how the family history gains personal meaning. Participants described 2 related concepts about personal relationships within a family that were important influences along the route to feeling at risk. These relationships may be countered by factors that limit the personal meaning of the family history.

Perceived closeness. Perceived closeness describes an emotional bond and continuity of their relationship, even when physically separated. Closeness often underpinned the emotional impact of witnessing a relative's illness.

"Dad moved down to London, and we'd go down to see him a couple of times a month, so we were close, you know, in seeing each other and talk, but we weren't close, you know touchy-feely close, which I do regret now that he has gone" (ID29; female; 33 years).

"I shared a lot of characteristics with [my mother], but I didn't identify in quite the same way as with [my father], although I was close to her" (ID06; female; 58 years).

The converse of closeness limited the personal importance of a relative's illness to the extent that the participant was unable to recall events in a relative's life or the cause of death.

"I'm not quite sure what she died of to be honest. It's a terrible thing to say, isn't it? We weren't particularly close" (ID24; male; 37 years).

Likeness. The concept of likeness describes similarities with family members, particularly parents, not simply in terms of physical characteristics, but also in terms of personality, mannerisms, and feelings. Many participants felt more at risk of developing their parent's illness because of perceived likenesses with the affected parent. Likeness often extended from parents to include an overall affinity with either the maternal or paternal side of the family. This likeness to one side of the family was often linked to beliefs about illness risk.

"As I'm getting older I'm really starting to look like [my mum] now, and feel like her. I guess that it makes me think I am like her, and maybe I'm going to get the same as her" (ID09, female; 38 years).

"[The heart disease] definitely seems to be more in the male side of my family as opposed to the maternal" (ID24; male; 37 years).

Likeness was not obviously linked to the patient's sex, despite such illnesses as breast cancer being sex specific. Likeness of personality, mannerisms, and "ways to do things" were more important than physical simi- larities in determining a personal sense of illness risk (as shown in Supplemental Table 2, which is available online only at http:/www.annfammed.org/cgi/ content/full/3/5/405/DC1). There were no participants who described feeling that a lack of similarity with an affected parent protected them from the illness in the family.

Reducing the personal meaning of the family history. When considering the personal meaning of their family history, some participants sought ways to minimize their sense of vulnerability through bargaining, and identifying counterexamples.

"I always had the feeling that I would get [Parkinson's like my father]. So I suppose maybe it was a bargain, you know, I don't want to get breast cancer [like my mother] but I'm happy to get Parkinson's, because I've had a lot of friends who've had breast cancer and it's really awful" (ID06; female; 58 years).

"I don't think you can ever prevent [the heart disease in my family] because I've nursed people who've had cardiac arrests running the London marathon, and they were obviously very fit people" (ID 11; female; 38 years).

The existence of a current illness and increasing age appeared to reduce the threat of their family history to the degree that their concerns shifted toward their current personal health and that of future generations.

Vulnerability in other family members. Despite the belief that a familial tendency had come "down the line" to themselves, only a minority of participants expressed concern that the familial illness would go on down the line to their children.

"You never think about your kids having [heart disease like my Dad], just don't, although I must admit I fully expected for [my child] to get the asthma because my sister's got 4 children and 3 of them had it" (ID08; male; 39 years).

"I think I worry whether I've got anything that I don't want to pass on to my children. They all know that I've been on this genetic thing [screening for bowel cancer]. I don't want to worry them too much, to feel that they may have to go through the same process" (ID07; female; 44 years).

While not necessarily considering the next generation, some participants identified other family members, most commonly siblings, as being more at risk, particularly those who had a family history of coronary artery disease or diabetes, perhaps because environmental or lifestyle factors were seen as more important in triggering the familial illness than for cancer.

"I think [my brother]'s a classic example of being an at-risk [for heart disease] person because to me he's just a younger version of my Dad. He smokes, he goes out for a drink, and he's in quite a high-up job which 
is very, very stressful, and I would say his weight isn't ideal, a bit over weight" (ID29; female; 33 years).

\section{Controlling the Familial Risk: 'How Can I Reduce My Risk?'}

Attempts were made to take control of the threat of

a family history through a variety of means: changing behavior, medication, screening, and obtaining information about the disease. Notions of fatalism, however, sometimes countered their beliefs in the ability to control their disease risk.

"Some things we don't have a choice about, but there are choices that we can make about keeping us in a healthy way.... I think that it basically comes back to just living a balanced normal lifestyle, and I believe if you add to it continuously by being overweight or not exercising at all or drinking too much or smoking, you are putting yourself more at risk" (ID22; female 45 years).

Perhaps given the greater emphasis on healthy behaviors for cardiovascular disease prevention, there was a greater sense of empowerment to control disease risk in those with a family history of coronary artery disease and diabetes than in those with a family history of cancer:

"There are types of cancer that you know in the end you can't beat. It's almost like that seems to be more of a threat [than heart disease], it's more worrying" (ID04; female; 56 years).

"I believe you have the power, if you like, to decide what your future direction is going to be. I am not going to die at 54 of a heart attack like my Mum did because I told myself that I have to do something about it to make sure I don't. It's a bit as though, yes you can inherit certain things, but then you take charge of it yourself" (ID17; female; 38 years).

Alternative strategies of control for participants with a family history of coronary artery disease and diabetes included medication or surgery, believing that this would provide them safety from their familial risk.

"I used to [feel at risk] until I had my heart bypass, and now I'm taking medication I feel quite safe. Although anybody can have a heart attack any time, I feel a little bit safer now because I've had mine seen to, so it doesn't worry me so much" (ID 15; male; 62 years).

The perceived inability to alter cancer risk through lifestyle changes led to participants with a family history of cancer relying more on screening and self-examination or seeking control by keeping well informed.

"I would have wanted some sort of blood test to decide whether I was genetically more predisposed to this [breast] cancer or whether the history was just coincidental in the family. And what I worked out (which probably wasn't accurate in retrospect) was that
I couldn't find out for sure whether it was a gene thing because I hadn't got any living relatives with breast cancer ... but I'm too scared to, actually, do breast checks on myself, I don't actually explore to see if I've got any lumps" (ID05; female; 60 years).

"I think we just wanted to be as educated as we could about [our family history of breast cancer], as in having surveillance or screening or just finding out what all this was, yeah, I just wanted information to tell me what my options were. That's just about as much you can do really, rather than maybe just being ignorant and not being informed" (ID10; female; 38 years).

\section{DISCUSSION}

This qualitative study of primary care patients explored how a person understands and makes sense of familial risk of common chronic disease. A theoretical model derived from specialist care was tested with general practice patients: not only were the constructs of the theoretical model confirmed, but also further themes emerged that have been used to refine the model, including concepts about personal relationships within a family that determine a sense of risk, the effects of personal experience of familial illness on risk perception, and strategies patients apply to cope with or control their familial risk (Figure 1).

Variations between patient perceptions and professional assessment of familial risk have been previously identified ${ }^{17}$ for coronary artery disease. This study shows that particular features occur across the spectrum of common chronic diseases. Whereas both health professionals and patients count the number of affected relatives and the age at which they were affected, ${ }_{1}{ }^{14}$ patients' understanding of familial risk can be informed by many more factors. The emotional impact of witnessing the relative's illness, plus features of the course of the relative's disease, were far more important to patients' personal sense of disease risk. For instance, the notion of a premature death was widely held. Many patients minimized their perceived risk by balancing disease risk with counterexamples, such as the relative who smoked and lived to old age, or factors that could protect them, such as medication or diet.

Patients' understanding about the causes of an illness in the family have an important effect upon a developing sense of personal risk. When considering what a family history means, most participants held a multifactorial model of familial risk, balancing the risks of nature and nurture. This study shows that understanding the mechanisms of inheritance was important only to the minority who were concerned about the risk of familial illness. Many more participants were concerned about their familial risk "coming down the 
line," referring to illnesses passing through the generations to themselves and their siblings. Fewer participants identified concerns that the risk of such diseases might be transmitted to their children or future generations, seeing themselves as the terminus. This finding contrasts with studies of patients from genetics clinics, who are concerned about the risk to their offspring as much as to themselves. ${ }^{18}$ Except for the rare subsets of disease inherited in a Mendelian fashion (eg, familial hypercholesterolemia, familial breast cancer BRCA1 and BRCA2), patients probably do not require in-depth knowledge of genetic mechanisms to understand their familial risk. ${ }^{19}$ Indeed, a multifactorial model is probably more appropriate for those with a family history of common chronic disease.

In this study we identified 2 concepts about personal relationships within a family-closeness and likeness - that affect understanding familial risk and were discussed in detail by all participants. Closeness to the affected relative underpinned the importance of emotional bonds to developing a sense of personal risk. The emotional impact of witnessing a relative's illness and the nature of the disease itself were important determinants of risk perception, ${ }^{20}$ with a strong negative impact leading to a higher sense of vulnerability. The emotional impact of a delayed diagnosis or sudden death probably reflects similar affective pathways to developing a personal sense of disease risk. We therefore suggest that closeness is related to the salience and perceived seriousness of the disease. On the other hand, likeness was more related to perceived susceptibility. Persons with a family history of coronary artery disease have been shown to view familial risk as linked to inheritance of physical characteristics. ${ }^{21,22}$ Our findings suggest that similar views were held by those with a family history of cancer or diabetes. Likeness or personality and mannerisms were more important than physical similarities in determining a sense of disease risk among our sample in contrast to the existing literature. Patients also identified characteristics within a particular side of the family that were not sex specific which informed their personal sense of disease risk.

The impact of personal experience on risk perception has been described among persons who have a relative with cancer, ${ }^{23,20}$ but the same does not hold true for diabetes or coronary artery disease. Those with a diabetic parent frequently underestimate their personal risk and know little about preventive strategies, such as diet and exercise. ${ }^{24}$ Persons with a family history of coronary artery disease consider visible risk factors such as smoking and weight to explain or predict coronary events and identify "coronary candidates" in their family. ${ }^{25}$ There is also acceptance, however, that these behavioral risk factors fail to explain some "anomalous deaths" in persons with low-risk lifestyles, and long "unwarranted" survival in those with high-risk lifestyles. ${ }^{26}$ Our findings are the same for participants with family histories of diabetes or coronary artery disease: both groups used counterexamples or strategies such as bargaining to minimize their perceived personal risk. These tactics can undermine a person's belief in the value of modifying behaviors to reduce their risk. ${ }^{25}$

Fatalistic attitudes toward disease risk were fairly common, particularly for cancer, which was perceived to be under less personal control, with fewer modifiable lifestyle risk factors. Notions of fatalism, though, were also used to account for continued risky lifestyles, such as smoking despite a family history of coronary artery disease. Representations of fatalism have been described among persons with familial hypercholesterolaemia, ${ }^{27}$ an autosomal dominant condition associated with a high risk of coronary artery disease. Such fatalistic attitudes associated with beliefs about familial risk may interfere with behavioral or lifestyle interventions even in multifactorial disease.

\section{Strengths and Limitations}

Our study is the first to explore primary care patients' views about their family history of 3 different common chronic diseases. Few studies have examined patients' understanding of familial risk of any chronic disease, and previous research, particularly among those with a family history of cancer, may have been influenced by the setting of a genetics clinic. The choice of a qualitative method to characterize the patients' perceptions is therefore not only appropriate but also novel in identifying themes that are generalized across diseases.

The sampling strategy led to a broad group of participants of varying age and educational levels. Recruitment through general practice records meant that we had to rely on random sampling, which led to a more homogenous sample than we had hoped for. Although we would have preferred a purposeful stratified sampling strategy, it was not possible within the restrictions of current UK ethics and research governance guidelines. Further strength was given by the interviews continuing until there was saturation of data, and analysis by 2 researchers increased validity. Given that the low response rate and the location of the study led to less ethnic variation than is found in the UK today, ${ }^{28}$ these results may not necessarily be extrapolated to other ethnic or cultural groups or countries. Furthermore, taking part in the research process itself may have increased or decreased participants' concerns about their risks.

The findings of our study have been fed back to the participants in a pilot questionnaire for further validation, and the data generated will form part of a larger 
quantitative study designed to measure the determinants of familial risk perception. This study will also address issues that emerged from these data, such as the influence of the "side of the family," sex of affected relative, and concepts of closeness and likeness on perceived familial risk and changes in behavior.

\section{Implications for Clinical Practice}

Our findings highlight potential differences between the way patients and clinicians determine and understand familial risk of common chronic disease. Studies of women with a family history of breast cancer suggest they often overestimate their risk and have associated high levels of anxiety. ${ }^{29}$ Furthermore, although cancer risk counseling can improve knowledge, a systematic review of the literature failed to show improvements in risk perceptions. ${ }^{30}$ Family history of diabetes and coronary artery disease may not be perceived as an important risk factor by some patients or may be used to downplay the value of behavior change.

Testing the theoretical model in a primary care setting and across multiple chronic conditions served not only to confirm the original constructs but also to add new constructs and refine the model of familial risk perceptions. We have shown that personal experiences of disease and their emotional impact can have a major influence on a patient's personal sense of vulnerability. This finding has considerable clinical value: health professionals may gain a better understanding of a patient's risk perception by exploring beliefs and experiences of disease within the patient's family. Such findings are consistent with the core values of the patient-centered clinical method ${ }^{4}$ and clinical narrative medicine. ${ }^{31}$ Risk communication strategies are being developed to assist physicians communicate risks clearly and more effectively and thereby to build closer relationships with their patients. ${ }^{32,33}$ Computerized tools have also been developed to support risk assessment of certain cancers, ${ }^{34}$ coronary artery disease, ${ }^{35}$ and diabetes. ${ }^{36}$ Incorporating the specific beliefs and experiences that determine patients' familial risk perceptions could improve their understanding about their risk and support informed decisions about the management of their risk through healthy behaviors and appropriate use of screening tests.

To read or post commentaries in response to this article, see it online at http://www.annfammed.org/cgi/content/full/3/5/405.

Key words: Primary health care; attitude to health; disease susceptibility; patient-centered care; risk factors; risk perception; medical history taking; patients' understanding; family health; family history; cancer; coronary arteriosclerosis; diabetes mellitus

Funding support: Fiona Walter is funded by a NHS RED Health Service Research Fellowship, and Jon Emery was funded by Cancer Research UK.
Acknowledgments: The authors would like to thank all the patients who kindly agreed to be interviewed, and the 2 practices for providing study patients. We also thank Professor Theresa Marteau and the 3 anonymous reviewers for their helpful comments about this paper.

\section{References}

1. Department of Health. NHS National Service Frameworks. 2001. Available at: http://www.dh.gov.uk/PolicyAndGuidance/HealthAnd SocialCareTopics/fs/en..

2. Kinmonth AL, Reinhard J, Bobrow M, Pauker S. The new genetics. Implications for clinical services in Britain and the United States. BMJ. 1998:316:767-770.

3. Emery J, Hayflick S. The challenge of integrating genetic medicine into primary care. BMJ. 2001;322:1027-1030.

4. Stewart M. Towards a global definition of patient centred care. BMJ. 2001;322:444-445.

5. Helman C. The culture of general practice. Br J Gen Pract. 2002; 52:619-620.

6. Richards MPM. Families, kinship and genetics. In: Marteau TM, Richards MPM, eds. The Troubled Helix. Social and Psychological Implications of the New Genetics. Cambridge: Cambridge University Press; 1996:249-273.

7. Bottorff JL, Ratner PA, Johnson JL, Lovato CY, Joab SA. Communicating cancer risk information: the challenges of uncertainty. Patient Educ Couns. 1998;33:67-81.

8. Leventhal H, Benyamini Y, Brownlee S. Illness representations: theoretical foundations. In: Petrie KJ, Weinman J, eds. Perceptions of Health and IIIness: Current Research and Applications. Amsterdam: Harwood; 1997:19-46.

9. Petrie KJ, Weinman J. Introduction to the perceptions of health and illness. In: Petrie KJ, Weinman J, eds. Perceptions of Health and IIIness: Current Research and Applications. Amsterdam: Harwood; 1997:1-17.

10. Walter FM, Emery J, Braithwaite D, Marteau TM. Lay understanding of familial risk of common chronic diseases: a systematic review and synthesis of qualitative research. Ann Fam Med. 2004;2:583-594.

11. QSR NUD*IST 4 User guide. 2nd ed. London: Sage Publications; 1997.

12. Ritchie J, Spencer L. Qualitative data analysis for applied policy research. In: Bryman A, Burgess RG, eds. Analyzing Qualitative Data. London: Routledge; 1994:173-194.

13. Glaser B, Strauss A. The Discovery of Grounded Theory. Chicago, III: Aldine; 1967.

14. Familial breast cancer, clinical guidelines. National Institute for Clinical Excellence, NHS; 2004. CG014. Available at: http://www.nice.org. uk/pdf/CG014niceguideline.pdf.

15. Jones R, Kennedy R, Hodgson S, et al. Guidelines for the early detection of colorectal cancer in primary care: information for general practitioners and health authorities. 1998. Available at: http://www. patient.co.uk/showdoc/40002353/.

16. Scottish Intercollegiate Guidelines Network. Management of colorectal cancer. 2003. Available at: http://www.sign.ac.uk/guidelines/fulltext/67/index.html.

17. Hunt K, Emslie C, Watt G. Lay constructions of a family history of heart disease: potential for misunderstandings in the clinical encounter? Lancet. 2001;357:1168-1171.

18. Lerman C, Seay J, Balshem A, Audrain J. Interest in genetic testing among first-degree relatives of breast cancer patients. Am J Med Genet. 1995; 57:385-392.

19. Emery J, Kumar S, Smith H. Patient understanding of genetic principles and their expectations of genetic services within the NHS: a qualitative study. Community Genet. 1998;1:78-83. 
20. Chalmers K, Thomson K. Coming to terms with the risk of breast cancer: perceptions of women with primary relatives with breast cancer. Qual Health Res. 1996;6:256-282.

21. Davison C, Frankel S, Davey Smith G. Inheriting heart trouble : the relevance of common-sense ideas to preventive measures. Health Educ Res. 1989;4:329-340.

22. Emslie C, Hunt K, Watt G. 'I'd rather go with a heart attack than drag on': lay images of heart disease and the problems they present for primary and secondary prevention. Coronary Health Care. $2001 ; 5: 25-32$.

23. Rees G, Fry A, Cull A. A family history of breast cancer: women's experiences from a theoretical perspective. Soc Sci Med. 2001;52:1433-1440.

24. Pierce $M$, Harding D, Ridout D, Keen H, Bradley C. Risk and prevention of type II diabetes: offspring's views. Br J Gen Pract. 2001;51:194-199.

25. Davison C, Davey-Smith G, Frankel S. Lay epidemiology and the prevention paradox: the implications of coronary candidacy for health education. Sociol Health IIIn. 1991;13:119

26. McConnachie A, Hunt K, Emslie C, Hart C, Watt G. "Unwarranted survivals" and "anomalous deaths" from coronary heart disease: prospective survey of general population. BMJ. 2001;323:1487-1491.

27. Senior V, Marteau TM, Peters TJ. Will genetic testing for predisposition for disease result in fatalism? A qualitative study of parents responses to neonatal screening for familial hypercholesterolaemia. Soc Sci Med. 1999:48:1857-1860.
28. Office National Statistics (ONS). Time Series Data. 2004. Available at: http://www.statistics.gov.uk/statbase/tsdintro.asp.

29. Hopwood P. Breast cancer risk perception: what do we know and understand? Breast Cancer Res. 2000;2:387-391.

30. Braithwaite D, Emery J, Walter F, Prevost AT, Sutton S. Psychological impact of genetic counseling for familial cancer: a systematic review and meta-analysis. J Natl Cancer Inst. 2004;96:122-133.

31. Greenhalgh T. Narrative based medicine: narrative based medicine in an evidence based world. BMJ. 1999;318:323-325.

32. Paling J. Strategies to help patients understand risks. BMJ. 2003; 327:745-748

33. Gigerenzer G, Edwards A. Simple tools for understanding risks: from innumeracy to insight. BMJ. 2003;327:741-744.

34. Emery J, Walton R, Murphy $\mathrm{M}$, et al. Computer support for interpreting family histories of breast and ovarian cancer in primary care: comparative study with simulated cases. BMJ. 2000;321:28-32.

35. Montgomery AA, Fahey T, Peters TJ, MacIntosh C, Sharp DJ. Evaluation of computer based clinical decision support system and risk chart for management of hypertension in primary care: randomised controlled trial. BMJ. 2000;320:686-690.

36. Griffin SJ, Little PS, Hales CN, Kinmonth AL, Wareham NJ. Diabetes risk score: towards earlier detection of type 2 diabetes in general practice. Diabetes Metab Res Rev. 2000;16:164-171.

\section{CHANGE-OF-ADDRESS FORM FAMILY MEDICINE}

Please complete this form and mail to the following address or fax to Annals Circulation at 913-906-6080:

Annals of Family Medicine, Circulation Department, 11400 Tomahawk Creek Pkwy, Leawood, KS 66211-2672

Check if member of sponsoring organization: $\square$ AAFP $\square$ ABFM $\square$ STFM $\square$ ADFM $\square$ AFMRD $\square$ NAPCRG

ID number from label on your journal cover $-\ldots-\ldots-$

OLD Information (Please print.)

Name

Company (if applicable)

Address (Street plus Apt or Ste)

City

Country

Postal Code (9-digit ZIP for US)

Telephone

Fax

E-Mail
NEW Information (Please print.)

\begin{tabular}{ll}
\hline Name \\
\hline Company (if applicable) \\
\hline Address (Street plus Apt or Ste) \\
\hline City \\
\hline Country Postal Code (9-digit ZIP for US) \\
\hline Telephone \\
\hline E-Mail \\
\end{tabular}

